\title{
BMJ Open Is there variation in private payor payments to cancer surgeons? A cross- sectional study in the USA
}

\author{
Tasce Bongiovanni (D) , ${ }^{1,2,3}$ Simon P Kim, ${ }^{4}$ Anthony Kim, ${ }^{5}$ Brigid Killelea, ${ }^{5}$ \\ Cary P Gross ${ }^{2,6}$
}

To cite: Bongiovanni T, Kim SP, Kim A, et al. Is there variation in private payor payments to cancer surgeons? A cross-sectional study in the USA. BMJ Open 2020;10:e035438. doi:10.1136/ bmjopen-2019-035438

- Prepublication history for this paper is available online. To view these files, please visit the journal online (http://dx.doi. org/10.1136/bmjopen-2019035438).

Received 21 February 2020 Revised 27 July 2020 Accepted 13 August 2020

Check for updates

(C) Author(s) (or their employer(s)) 2020. Re-use permitted under CC BY-NC. No commercial re-use. See rights and permissions. Published by BMJ.

For numbered affiliations see end of article.

Correspondence to Dr Tasce Bongiovanni; Tasce.bongiovanni@ucsf.edu

\section{ABSTRACT}

Objectives Although demand for price transparency in healthcare is growing, variation in private payors' payments to surgeons for oncologic resection has not been well characterised. Our aim was to assess variation of private payors' payments to surgeons for cancer resection using data based on fee-for-service allowed amounts, billed by a large mix of commercial payors and third-party administrators.

Setting Fair Health (FH), an independent, not-for-profit organisation that collects and compiles claims data from payors nationwide. FH maintains the nation's largest repository of privately billed medical and dental claims representing over 125 million covered lives in the USA. Participants We performed a cross-sectional study assessing private payer data for five common types of cancer surgery: simple mastectomy (SM), modified radical mastectomy (MRM), open lobectomy, video-assisted thoracoscopic surgery (VATS) lobectomy and radical prostatectomy during 2012 and 2013.

Primary and secondary outcome measures To assess variation across regions, we compared regional median allowed payments. To assess intraregion variability, we evaluated the distribution of regional IQRs of allowed payments.

Results Median allowed payments varied substantially across regions. For SM, median allowed payments ranged from $\$ 550$ in the least expensive to $\$ 1380$ in the costliest region. For MRM, the range was $\$ 842-\$ 1760$, for lobectomy \$326-\$3066, for VATS \$317-\$3307 and for prostatectomy $\$ 1716-\$ 4867$. There was also substantial variation within geographic areas. For example, the mean IQRs in surgeon payment within regions were: SM \$577 (25th percentile) to $\$ 1132$ (75th percentile); MRM \$850\$1620; lobectomy \$861-\$2767; VATS \$1024-\$3122; and prostatectomy \$2286-\$3563.

Conclusions There is a wide range of variation both across and within geographic regions in allowed amounts of surgeon payments for common oncologic resections. Transparency about these allowed amounts may have a profound impact on patient and employer choice and facilitate future assessments of value in cancer care.

\section{BACKGROUND}

Given the rapidly rising costs of cancer care, ${ }^{1}$ it is increasingly important to understand the costs of surgical resection, a mainstay of

\section{Strengths and limitations of this study}

- Cross-sectional study assessing private payer data for five common types of cancer surgery: simple mastectomy, modified radical mastectomy, open lobectomy, video-assisted thoracoscopic surgery lobectomy and radical prostatectomy.

- Regional variation assessed.

Intraregion variability assessed.

Median allowed payments are a derived amount.

oncologic treatment. Further, healthcare price transparency is a growing movement, ${ }^{2}$ empowering healthcare consumers to better understand what they pay for services. While spending variation in Medicare has been attributed to overutilisation of services, ${ }^{3}$ variation in costs of care among the privately insured is largely affected by differences in the amount of payments for services. ${ }^{4}$ Importantly, variation in cost directly affects patients, as payments for surgical procedures often exceed most annual deductibles, ${ }^{5}$ and employers have begun to shift more costs to employees $^{256}$ by experimenting with novel benefit designs to include the consumer in the healthcare decision-making process. ${ }^{5}$

Payment variation directly affects patients, as employers are shifting more costs directly to employees. ${ }^{256}$ Some employers are shifting to narrower networks, resulting in substantial out-of-pocket costs for patients seeing 'out-ofnetwork' providers. ${ }^{7-10}$ These out-of-network provider payments are often based on industry standards, known as 'allowed amounts'. In other instances, private payers are taking a more targeted approach by setting specific cost-sharing targets. These 'reference-based pricing' plans require patients to pay the difference for using a higher cost facility. ${ }^{5}$ One prominent example, the California Public Employees Retirement System, health insurer to 1.3 million California state employees, saw a reduction in spending by 
$\$ 6$ million over the first 2 years of reference-based pricing for specific surgical procedures. ${ }^{11}$ All of these payment reforms increase financial risk and exposure to patients, leading to a greater need to incorporate costs into their healthcare decision-making.

It is well known that the USA has one of the most expensive healthcare systems in the world. However, price transparency is an issue for many nations. For example, countries throughout the European Union, New Zealand and Australia have begun to explore price transparency, especially with regard to the pharmaceutical industry pricing of medications. ${ }^{12-14}$ As healthcare costs rise around the world, we expect that this issue will quickly become important across multiple types of health systems.

Though variation in Medicare payments in the USA has been widely described, ${ }^{34}$ private payer data have traditionally been unavailable to both the public and research communities. Therefore, little is known about variation in payments to surgeons in the private payer world, and even less about variation in these payments for oncologic resections. As the number of patients with cancer is growing, as well as the cost of caring for each patient, ${ }^{1} 1516$ payments to surgeons for oncologic resections will become ever more important. To provide a clear understanding of these payments, we used industrybased allowed amount benchmarks of surgeon payments to elucidate (1) nationwide variation of private payer allowed amounts of surgeon payments for cancer resection, and (2) variation within geographical areas of these payments.

\section{METHODS}

We performed a cross-sectional study, based on private payers' allowed amount benchmarks of payments to surgeons, compiled from a large mix of private payer and third-party administrator data, over 2012 and 2013. We licensed these data from Fair Health (FH), an independent, not-for-profit organisation that collects and compiles claims data from payers nationwide. FH maintains the nation's largest repository of privately billed medical and dental claims representing over 125 million covered lives. ${ }^{17-19} \mathrm{FH}$ data are robust and widely used by a variety of stakeholders in the healthcare industry to inform the creation of fee schedules, assist in claims adjudication and resolve provider disputes. ${ }^{17} 18$

We selected common surgical resections for the three non-skin cancers estimated to be most frequently diagnosed in 2015: breast, lung and prostate. ${ }^{16}$ We then evaluated the 'allowed amount' that was reimbursed to the surgeon, as derived by FH through an 'allowed medical benchmark' (AMB). The AMB is based on the payers' maximum allowed amount of surgeon payment for a specific procedure. First, these allowed amounts are compiled into 491 nationwide 'geozips' or 'regions', based on groupings of the first three digits of ZIP codes. Then, groupings of similar procedures are created, and relative value units (RVUs) applied to each type of

\begin{tabular}{|c|c|}
\hline CPT code & Procedure \\
\hline 19303 & Simple mastectomy \\
\hline 19307 & Modified radical mastectomy \\
\hline 32480 & Open lobectomy \\
\hline 32663 & $\begin{array}{l}\text { Video-assisted thoracoscopic surgery } \\
\text { lobectomy }\end{array}$ \\
\hline 55866 & Radical prostatectomy \\
\hline
\end{tabular}

CPT, Current Procedural Terminology.

procedure. ${ }^{17} 18$ A conversion factor is applied to each grouping, and the derived amount is calculated into percentiles, by geographic region, based on each procedure's RVUs. ${ }^{178}$ Therefore, the AMB is an estimate of the allowed amount of surgeon payment for a specific procedure, avoiding disclosure of the actual amount different payers are reimbursing. The AMB is currently used in New York state as a consumer protections benchmark and has been used to support other state programmes. ${ }^{17-19}$

We selected common resections for each cancer and identified surgery claims using Current Procedural Terminology codes for simple mastectomy (SM), modified radical mastectomy (MRM), open thoracotomy for wedge resection or lobectomy, video-assisted thoracoscopic surgery (VATS) and robotic radical prostatectomy (table 1). For each procedure, we included regions with $>20$ procedures in the broader AMB cost analysis group. To further reduce bias in our estimates, we then dropped regions with $\leq 10$ procedures for SM, MRM and prostatectomy, and $\leq 5$ procedures for lobectomy and VATS. As private payer data have been relatively unstudied, we included Medicare reported median payments from the Centers for Medicare and Medicaid Services public use file as a point of reference. ${ }^{20}$

To assess variation, we evaluated the distribution of regions' median allowed amounts. We also assessed SDs, and to characterise a unitless dispersion of the median amounts, calculated the coefficient of variation for each procedure. To assess intraregion variability, we compared means of intraregion IQRs of allowed amounts.

\section{Patient and public involvement}

The development of this research question was based on patient and public interest in informed and transparent healthcare costs. While we did not involve patients directly in the design or conduct of the study, patients are the focus of $\mathrm{FH}$, and well as the study we conducted. Patients should be able to find and evaluate reliable information about healthcare costs, which at this time in the USA is difficult. We hope that dissemination of our study will help to elevate this issue.

\section{RESULTS}

Our full sample of private payer data included almost 25000 procedures. After applying our strict inclusion and 


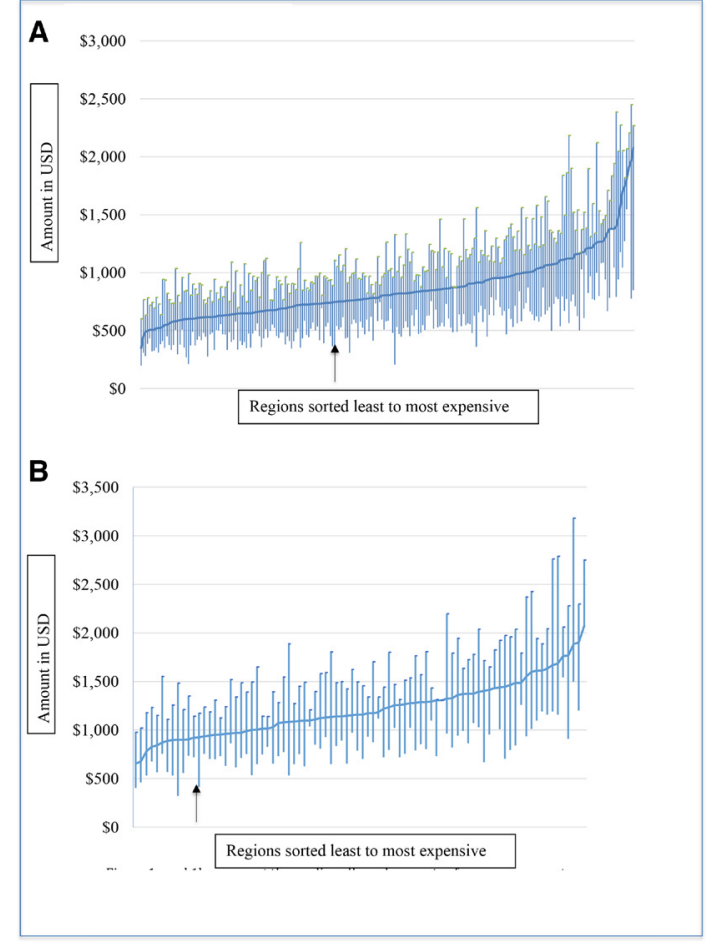

Figure 1 Variation in surgeon payments for breast cancer resections. (A) Simple mastectomy. (B) Modified radical mastectomy. (A) and (B) represent the median allowed amounts of surgeon payments across all included regions (the horizontal blue line), as well as the IQR (the vertical lines) within each region. The black arrow represents the Medicare median payment. USD, US dollars.

exclusion criteria to this sample, we had 2077 distinct procedures. Our sample included 230 distinct regions for SM, 86 distinct regions for MRM, 68 for lobectomy, 44 for VATS and 165 for prostatectomy.

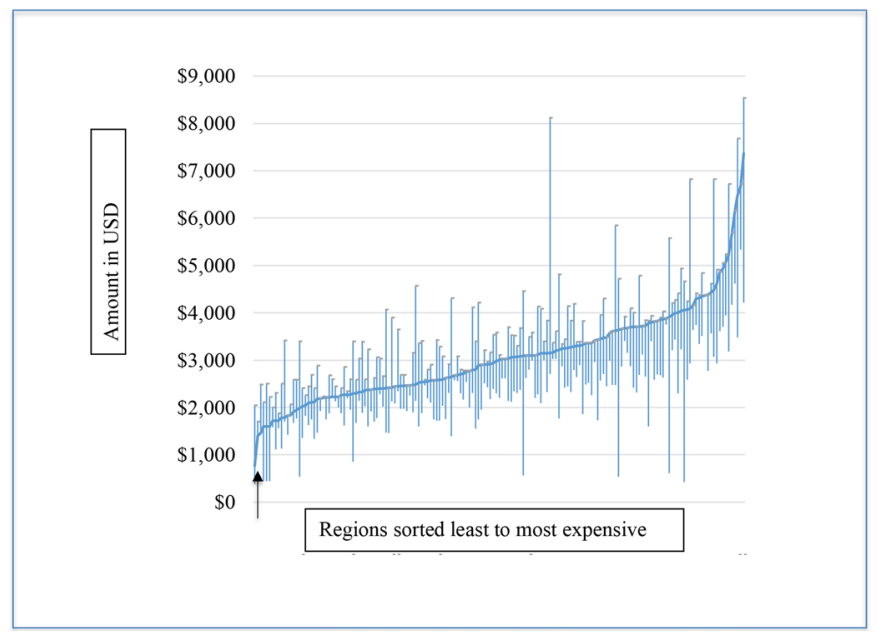

Figure 3 Variation in surgeon payments for prostate cancer resection: radical prostatectomy. This figure represents the median allowed amounts of surgeon payments across all included regions (the horizontal blue line), as well as the IQR (the vertical lines) within each region. The black arrow represents the Medicare median payment. USD, US dollars.

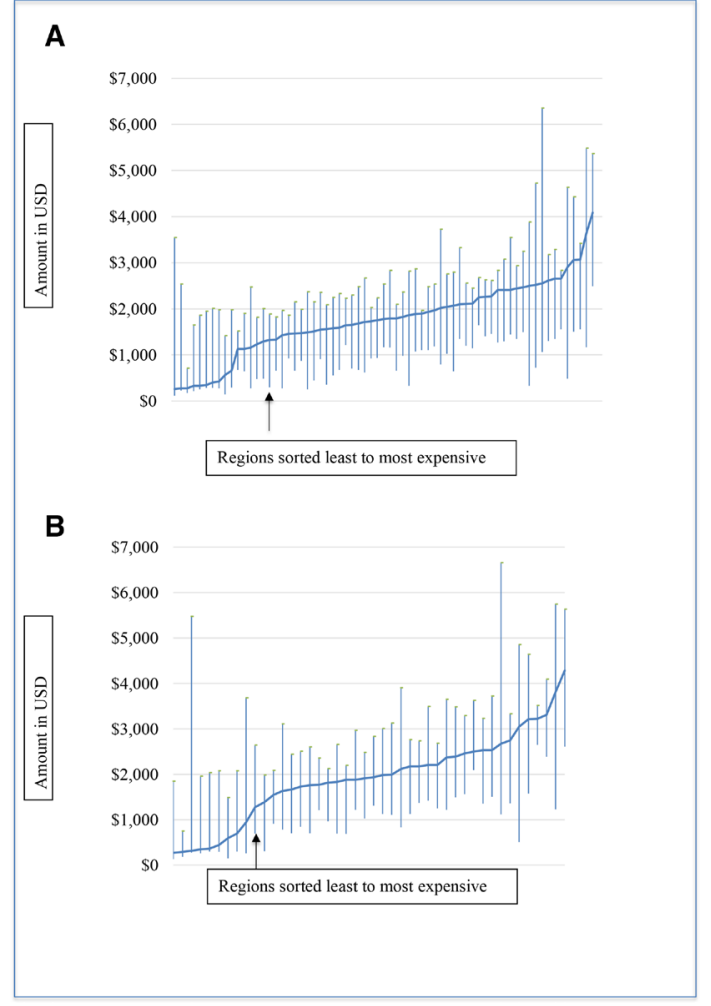

Figure 2 Variation in surgeon payments for lung cancer resections. (A) Open lobectomy. (B) Video-assisted thoracoscopic surgery lobectomy. (A) and (B) represent the median allowed amounts of surgeon payments across all included regions (the horizontal blue line), as well as the IQR (the vertical lines) within each region. The black arrow represents the Medicare median payment. USD, US dollars.

Overall, the median allowed amounts of surgeon payments were as follows: $\$ 805$ for SM, $\$ 1156$ for MRM, $\$ 1785$ for lobectomy, $\$ 1921$ for VATS and $\$ 3008$ for prostatectomy. For Medicare, the median nationwide payments for these oncologic resections are as follows: SM $\$ 734$, MRM $\$ 877$, lobectomy $\$ 1110$, VATS $\$ 1068$ and prostatectomy $\$ 1275 .{ }^{20}$

The median amounts varied substantially across regions. For SM, the median amount ranged from $\$ 550$ in the least expensive region to $\$ 1380$ in the costliest region. For MRM, the median amount ranged from $\$ 842$ to $\$ 1760$, for lobectomy $\$ 326$ to $\$ 3066$, for VATS $\$ 317$ to $\$ 3307$ and for prostatectomy $\$ 1716$ to $\$ 4867$ (figures 1-3). The SDs for these amounts were also quite wide. Among the median amounts alone, the SDs for both lung and prostate resections were approximately $\$ 1000$ (lobectomy $\$ 1045$, VATS $\$ 958$, prostatectomy $\$ 1010)$. The coefficients of variation were as follows: SM 25, MRM 24, lobectomy 57, VATS 50 and prostatectomy 33 (table 2).

In fact, the SDs for these allowed amounts of surgeon payments were also quite wide. Among the median allowed amounts alone, the SDs for both lung and prostate resections were approximately $\$ 1000$ (lobectomy $\$ 1045$, VATS $\$ 958$, prostatectomy $\$ 1010$ ).

The variation within geographic regions was also extensive. The mean interquartile values $(25$ th and 75 th 
Table 2 Variation of allowed amounts by procedure at the regional level

\begin{tabular}{|c|c|c|c|c|c|}
\hline Procedure & $\begin{array}{l}\text { Distinct } \\
\text { regions } \\
\text { (geozips) }\end{array}$ & $\begin{array}{l}\text { Nationwide } \\
\text { median } \\
\text { allowed } \\
\text { amount }\end{array}$ & $\begin{array}{l}\text { Range of } \\
\text { median allowed } \\
\text { amount }\end{array}$ & $\begin{array}{l}\text { SD (of the } \\
\text { median) }\end{array}$ & $\begin{array}{l}\text { Coefficient } \\
\text { of variation } \\
\text { (of the } \\
\text { median) }\end{array}$ \\
\hline Simple mastectomy & 230 & $\$ 805$ & $\$ 550-\$ 1380$ & $\$ 271$ & 25 \\
\hline Modified radical mastectomy & 86 & $\$ 1156$ & $\$ 842-\$ 1760$ & $\$ 285$ & 24 \\
\hline Lobectomy & 68 & $\$ 1785$ & $\$ 326-\$ 3066$ & $\$ 1045$ & 57 \\
\hline Radical prostatectomy & 165 & $\$ 3008$ & $\$ 1716-\$ 4867$ & $\$ 1010$ & 33 \\
\hline
\end{tabular}

VATS, video-assisted thoracoscopic surgery.

percentiles) within regions were as follows: for SM the mean 25th intraregional percentile charge was $\$ 577$ and the mean 75 th intraregional percentile charge was $\$ 1132$. For MRM, these values were $\$ 850$ and $\$ 1620$, for lobectomy $\$ 861$ and $\$ 2767$, for VATS $\$ 1024$ and $\$ 3122$ and for prostatectomy $\$ 2286$ and $\$ 3563$ (figures 1-3).

\section{DISCUSSION}

To our knowledge, this is the first study to directly examine variation in surgeon payment allowed amounts across common oncologic resections. We found that allowed amounts of surgeon payments from private payers vary widely across the country. We found that variation between regions was as high as $\$ 3000$, a 10-fold difference, and variation in the IQR within regions was as high as $\$ 2000$, representing a threefold difference. Further, median amounts were sometimes much higher than the Medicare median amounts. Importantly, we also found that variation in these amounts within regions was similarly striking, pointing to the fact that variation is not dependent on factors such as cost of living differences. Studies on variation in Medicare payments have not traditionally looked at intraregional variation, and have instead focused on variation by region, or at the individual hospital level.

This variation existed across all five oncologic resections we studied and was especially striking for lobectomy and VATS procedures.

Our study builds on prior work in important ways. Historically, private payer data have been considered proprietary and obscured from public view. Further, many studies of payment variation have focused on costs of inpatient hospitalisations, rather than direct payments to the surgeon. The few studies attempting to analyse payments for surgical procedures have had the difficult task of directly contacting individual hospitals or surgeons. ${ }^{21-27}$ For example, one study group attempted to elucidate surgeon payments for oncologic resection, but was only able to obtain payment estimates for $10 \%$ of the 70 contacted hospitals. ${ }^{23}$ Another study assessing surgeon and anaesthesia payments for radical prostatectomy found even wider variation than our study $(\$ 4282$ difference between lowest and highest payments). ${ }^{23}$ In fact, to our knowledge, no other studies to date have used private insurance data to examine individual physician payments for surgical procedures.

Our findings have important implications for both private payers and healthcare consumers. Payment data have been historically unavailable as a tool to aid patients in choosing their providers or hospitals. However, increasing the transparency of provider payments is crucial, especially in an area like cancer care where costs are often very high. Additionally, our findings show that there is a great deal of payment variation, which private payers are already seeking to control through high-deductible plans, reference-based pricing and narrow networks. Patients are becoming incentivised through these plans to think carefully about how their money is spent on healthcare.

Our study has important limitations. First, we have used a derived amount, not the actual payment for each procedure. However, these allowed amounts are becoming the industry standard and are already being used to provide transparency to consumers. ${ }^{19}$ Additionally, we did not adjust for regional differences in factors such as median income, or patientlevel differences such as benefit design, that could moderate the impact of cost differential on access. Nevertheless, we found considerable variation across and within regions, given credence to the fact that the variation cannot be solely explained by regional differences. Variation remained high even when the cost of living within a region was similar. Finally, our analysis is not linked to patient outcomes. While it is possible that wide payment variation is a reflection of quality, this has not been the case in real-life scenarios. ${ }^{5}$ Future work will be needed to study the relationship between cost variation and quality.

\section{CONCLUSIONS}

Our study found a wide range of variation both across and within geographic regions in the allowed amounts paid to surgeons for common oncologic resections. Our findings have important implications for both private payers and healthcare consumers. Given that payment data have been historically unavailable as a tool to aid patients in choosing their providers or hospitals, the substantial variation within 
and across regions underscores the importance of increasing provider payment transparency, especially in an area such as cancer care where overall costs are often very high. As the healthcare system moves towards increased patient responsibility for healthcare costs, it will be important to understand the impact of cost on patient access and choice for cancer care. Potential solutions for reining in cost and improving quality of cancer care will require access to reliable price information. ${ }^{21}$ Transparency about surgical payment for oncologic resection may have a profound impact on patient and employer choice and facilitate future assessments of value in cancer care.

\section{Author affiliations}

${ }^{1}$ Department of Surgery, University of California San Francisco School of Medicine, San Francisco, California, USA

${ }^{2}$ National Clinician Scholars Program, Yale University School of Medicine, New Haven, Connecticut, USA

${ }^{3}$ U.S. Department of Veterans Affairs, Connecticut Healthcare System, West Haven, Connecticut, USA

${ }^{4}$ University Hospital Case Medical Center, Case Western Reserve University, Urology Institute, Cleveland, Ohio, USA

${ }^{5}$ Department of Thoracic Surgery, Yale University School of Medicine, New Haven, Connecticut, USA

${ }^{6}$ Department of Internal Medicine, Yale University School of Medicine, New Haven, Connecticut, USA

Correction notice This article has been corrected since it was published. Middle initial has been added for author Cary Gross.

Twitter Tasce Bongiovanni @TasceB

Contributors TB analysed and interpreted the patient data regarding the AMB for each type of surgery, and wrote the draft manuscript. CG provided major oversight to the project and partnership and was a major contributor in writing the manuscript. BK, SPK and AK all contributed surgical expertise to the choice of procedures. All authors read and approved the final manuscript.

Funding CG has research funding from the NCCN Foundation (Pfizer/ AstraZeneca) - research funding paid to Yale University, Johnson and Johnsonresearch funding paid to Yale University, Genentech—research funding paid to Yale University, Flatiron-Travel/Speaking Reimbursement.

Competing interests None declared.

Patient consent for publication Not required.

Ethics approval The Human Investigation Committee at the Yale University School of Medicine in New Haven, CT approved the study as an exempted study.

Provenance and peer review Not commissioned; externally peer reviewed.

Data availability statement Data may be obtained from a third party and are not publicly available. The data sets generated and/or analysed during the current study are not publicly available due to the fact that they were provided under direct agreement via a MOA with $\mathrm{FH}$, but are available from the corresponding author on reasonable request. This was a partnership with $\mathrm{FH}$, approved by the Yale IRB. We cannot freely share the data in a public space. If researchers are interested in using the data, please contact the first author, TB. They will need to sign a data use agreement with $\mathrm{FH}$ and have the study approved by their own IRB.

Open access This is an open access article distributed in accordance with the Creative Commons Attribution Non Commercial (CC BY-NC 4.0) license, which permits others to distribute, remix, adapt, build upon this work non-commercially, and license their derivative works on different terms, provided the original work is properly cited, appropriate credit is given, any changes made indicated, and the use is non-commercial. See: http://creativecommons.org/licenses/by-nc/4.0/.
ORCID iD

Tasce Bongiovanni http://orcid.org/0000-0003-4568-2087

\section{REFERENCES}

1 Mariotto $A B$, Wang Z, Klabunde $C N$, et al. Life tables adjusted for comorbidity more accurately estimate noncancer survival for recently diagnosed cancer patients. J Clin Epidemiol 2013;66:1376-85.

2 Colella G. Hearing: 'high prices, low transparency: the bitter pill of health care costs'. Testimony of Giovanni Colella, MD, CEO and cofounder of Castlight Health, Inc. United States Senate committee on finance, 2013.

3 Institute of Medicine of the National Academies. Dartmouth Institute map of price adjusted Medicare PMPM spending by HRR. Dartmouth Atlas of Healthcare, 2008.

4 Care CoGViHCSaPoH-V. Variation in health care spending: target decision making, not geography. Institue of Medicine of the National Academies, 2013.

5 Robinson JC, Brown T, Whaley C. Reference-Based benefit design changes consumers' choices and employers' payments for ambulatory surgery. Health Aff 2015;34:415-22.

6 Hewitt A. Aon Hewitt employer survey, 2012. Available: http://aon. mediaroom.com/index.php?s=25776\&item $=132919$

7 Abelson R. Health insurance shoppers look to limited networks to save money. New York Times, 2015.

8 Blumenthal D. Reflecting on health reform - narrow networks: boon or bane? Fund TC, 2014.

9 President EOot. The burden of health insurance premium increases on American families, 2009.

10 Claxton GRM, Panchal N, Damico A, et al. Employer health benefits: 2014 survey. Henry J. Kaiser Family Foundation, 2014.

11 Practice DIfHPaC. Dartmouth atlas of health care data by region. Lebanon (NH): Dartmouth Institute, 2015.

12 Kyle MK, Ridley DB. Would greater transparency and uniformity of health care prices benefit poor patients? Health Aff 2007;26:1384-91.

13 Robertson J, Walkom EJ, Henry DA. Transparency in pricing arrangements for medicines listed on the Australian pharmaceutical benefits scheme. Aust Health Rev 2009;33:192-9.

14 Vogler S, Paterson KR. Can price transparency contribute to more affordable patient access to medicines? Pharmacoecon Open 2017;1:145-7.

15 Feinstein AJ, Long J, Soulos PR, et al. Older women with localized breast cancer: costs and survival rates increased across two time periods. Health Aff 2015;34:592-600.

16 American Cancer Society. Cancer facts and figures 2015. Atlanta, GA: American Cancer Society, 2015.

17 FAIR Health I. Fair health allowed medical benchmark guide, 2013.

18 FAIR Health I. User guide - FH benchmarks products, 2014.

19 FAIR Health I. NYS designates fair health data as an official reference point for consumer protections. FAIR Health, Inc, 2015.

20 The Centers for Medicaid and Medicare Services. Medicare fee-for service provider utilization \& payment data physician and other supplier public use file. The Centers for Medicaid and Medicare Services, 2014.

21 Rosenthal JA, Lu X, Cram P. Availability of consumer prices from US hospitals for a common surgical procedure. JAMA Intern Med 2013;173:427-32.

22 Willey JC, Reuter LS, Belatti DA, et al. Availability of consumer prices for bunion surgery. Foot Ankle Int 2014;35:1309-15.

23 Pate SC, Uhlman MA, Rosenthal JA, et al. Variations in the open market costs for prostate cancer surgery: a survey of US hospitals. Urology 2014;83:626-31.

$24 \mathrm{Kim}$ SP, Shah ND, Karnes RJ, et al. The implications of hospital acquired adverse events on mortality, length of stay and costs for patients undergoing radical cystectomy for bladder cancer. $J$ Urol 2012;187:2011-7.

25 Pasquali SK, Sun J-L, d'Almada P, et al. Center variation in hospital costs for patients undergoing congenital heart surgery. Circ Cardiovasc Qual Outcomes 2011;4:306-12.

26 Romley JA, Chen AY, Goldman DP, et al. Hospital costs and inpatient mortality among children undergoing surgery for congenital heart disease. Health Serv Res 2014;49:588-608.

27 Miller DC, Gust C, Dimick JB, et al. Large variations in Medicare payments for surgery highlight savings potential from bundled payment programs. Health Aff 2011;30:2107-15. 